\title{
Optimization of Agrobacterium-mediated transformation parameters for Melastomataceae spp. using green fluorescent protein (GFP) as a reporter
}

\begin{abstract}
Agrobacterium-mediated transformation for both Melastoma malabathricum and Tibouchina semidecandra were optimized using green fluorescent protein (GFP) as a reporter. The binary vector pCAMBIA1304 harboring the modified green fluorescent protein (mgfp) gene driven by the CaMV $35 \mathrm{~S}$ promoter was used. Parameters optimized were bacterial strain, bacterial concentration, pre-culture period, co-cultivation period, immersion time, acetosyringone concentration and wounding type. Results obtained were based on the percentage of GFP expression which was observed 3 days post-transformation. Agrobacterium tumefaciens strain LBA4404 and EHA105 at concentration $1 \times 107 \mathrm{cfu}$ ml-1 (OD600nm 0.8) showed the highest virulence on M. malabathricum and T. semidecandra, respectively. Four days of preculture and 2 days of co-cultivation were optimum for M. malabathricum transformation, while 3 days of pre-culture and co-cultivation for T. semidecandra. Result also showed that 60 min of immersion and addition of $200 \mu \mathrm{M}$ acetosyringone gave the highest percentage of positive transformants for both M. malabathricum and T. semidecandra. Mild wounding also significantly increased the efficiency of M. malabathricum transformation. (C) 2006 Elsevier B.V. All rights reserved
\end{abstract}

Keyword: Agrobacterium; Green fluorescent protein; Melastomataceae 